\title{
Erratum: Some Observations on the Effects of Sulfur and Active Elements on the Oxidation of $\mathrm{Fe}-\mathrm{Cr}-\mathrm{Al}$ Alloys*
}

\section{Forest and J. H. Davidson}

Figure 5 and Figure 6 were identified incorrectly. Each figure with its correct caption appears below and on the following page.

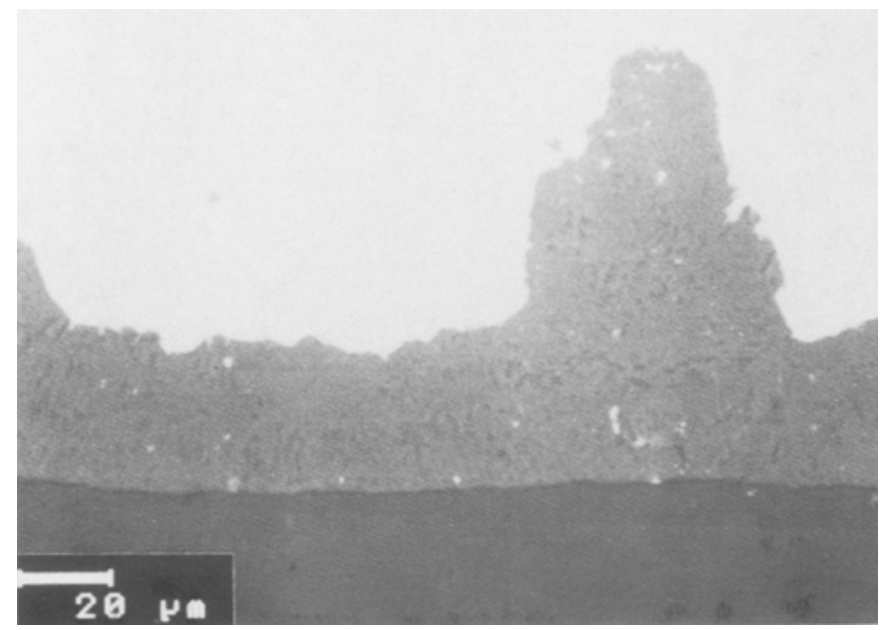

Fig. 5. Alloy 5 coupon oxidized $420 \mathrm{hr}$ at $1300^{\circ} \mathrm{C}$. Scanning electron micrograph.

\footnotetext{
${ }^{*}$ This paper originally appeared in Oxid. Met., 43, 479.
} 


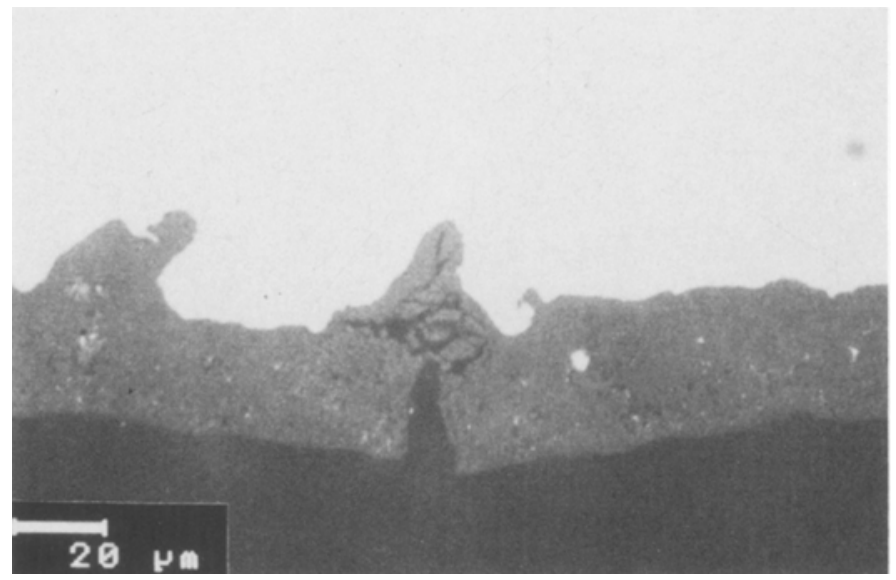

Fig. 6. Alloy 1 coupon oxidized $420 \mathrm{hr}$ at $1300^{\circ} \mathrm{C}$. Scanning electron micrograph. 